\title{
Identification of Potential Tumor Markers in Sudanese Breast Cancer Patients Using a Proteomic Approach
}

\author{
Amany Elamin ${ }^{1,2}$, Thomas Franz ${ }^{3}$ and Muntaser E Ibrahim ${ }^{1 *}$ \\ ${ }^{1}$ Institiute of Endemic Diseases, University of Khartoum, Sudan \\ ${ }^{2}$ Commission for Biotechnology and Genetic Engineering, National Center for Research, Sudan \\ ${ }^{3}$ Proteomics Core Facility, European Molecular Biology Laboratory (EMBL), Heidelberg, Germany
}

\begin{abstract}
Breast cancer $(\mathrm{BC})$ is considered as a major health problem in Sudan, being the most frequent hospital treated malignancy and the commonest cancer affecting Sudanese females (34\%). Proteomics provides tools that investigate the precise molecular defect(s) in breast cancer tissue. Moreover, it plays a growingly important role in tumor markers discovery. In this study, a proteomic assay (2D-PAGE) was used to investigate the protein profiles of a panel of 12 Sudanese breast malignant tissues and 12 matched controls. Protein spots of interest were excised manually, and in-gel digested using trypsin. Proteins were identified using mass spectrometry (MALDITOF). Mascot program was used to search protein databases for matching peptides from known proteins. The overall profile was relatively similar, the preliminary results identified three proteins to be differentially expressed, suggesting that they may perform a role in breast neoplasia. Although the number of samples investigated in this study is comparatively small, to allow authoritative conclusions, the study provided three proteins that might be potential tumor markers in Sudanese breast cancer patients requiring further investigations and validation.
\end{abstract}

Keywords: Breast cancer; Tumor markers; Proteomics; 2D-PAGE; Mass spectrometry

Abbreviations: 2DE: Two-Dimensional Gel Electrophoresis; a1AT: Alpha-1 Anti-Trypsin; DTT: Dithiothreitol; Pin1: Peptidylprolyl Cis-Trans Isomerase; PMF: Peptide Mass Fingerprinting; PrdxV: Peroxiredoxin V; ROS Reactive Oxygen Species; SDS PAGE: Sodium Dodecyl SulfatePolyacrylamide Gel Electrophoresis; MALDI TOF: Matrix Assisted Laser Desorption Ionization - Time of Flight; Mass Spectrometry; IPG: Immobilized pH Gradient; IEF: Iso-Electric Focusing

\section{Introduction}

Worldwide, breast cancer (BC) ranks as the top cancer among women, accounting for $23 \%$ of the total cancer cases and the principal cause of cancer death (14\%) among females [1]. In Sudan, breast cancer is considered as the most frequent hospital treated malignancy, accounting for about one-fifth of all cancers reported in both sexes [2]. Among Sudanese women, breast and cervical Cancers account for about $50 \%$ of all cancers [3].

Proteomic techniques are powerful tools to help in the identification of tumor markers. These markers are thought to be helpful in the clinical management of cancer patients, assisting in diagnostic, staging, evaluation of therapeutic response, detection of recurrence and metastasis, and the development of new treatment modalities [4]. There are few breast tumor markers being used routinely in clinics, such as follow up molecular markers (CA 15-3, CA 27.29 and CEA), markers of prognostic and/or therapeutic value (hormone receptors, HER-2, Ki-67, p53 proteins), and the genes for hereditary breast cancer [5]. Nevertheless, the number of biomarkers reaching routine clinical use remains unacceptably low. Therefore, the search is still ongoing for biomarkers to improve early and specific detection and disease monitoring [6]. The present study aims to investigate the protein profiles of a panel of Sudanese breast cancer tissues and controls, with the target of identifying proteins that could potentially be used as tumor markers.

\section{Materials and Methods}

This is a case-control hospital-based study. A panel of 12 Sudanese breast cancer patients (12 tumor-control pairs) were recruited in this study. Tissue biopsies were collected by Breast Cancer Research Group members at the Institute of Endemic Disease, University of Khartoum, from hospitals around Khartoum State. Both fresh normal and biopsy tissues had been obtained from breast cancer patients 20-30 min after surgery from patients who did not receive preoperative treatment following the appropriate ethical procedure. Tissue samples were snap frozen in liquid nitrogen prior to transport to the Molecular Biology $\mathrm{lab}$ at the Institute of Endemic Disease. The samples were stored in a $-80^{\circ} \mathrm{C}$ freezer. A fraction of each sample had been stored as archival material to be used for future needs.

\section{Sample preparation}

Tissue protein extraction had been accomplished at the Department of Molecular Biology, Institute of Endemic Disease, University of Khartoum, Sudan. Tissue Samples were homogenized by freezing with liquid nitrogen and hand grinding with a cooled mortar and pestle to a fine powder. An adequate amount of sample was suspended in lysis buffer (9 M Urea, 4\% CHAPS, 100 Mm DTT, 1\% Pharmalyte pH 3-10, and Protease inhibitor cocktail). The suspension was vortexed for 30 seconds to facilitate protein solubilization, incubated for 1 hour at room temperature, and centrifuged (16000 g, 30 minutes). The supernatant (crude extract) was transferred to a clean tube, stored at $20^{\circ} \mathrm{C}$.

*Corresponding author: Muntaser E. Ibrahim, Institute of Endemic Diseases,
University of Khartoum, Sudan, Tel: 24911793267; E-mail: mibrahim@iend.org Received October 17, 2016; Accepted October 25, 2017; Published October 27. 2017

Citation: Elamin A, Franz T, Ibrahim ME (2017) Identification of Potential Tumor Markers in Sudanese Breast Cancer Patients Using a Proteomic Approach. J Cancer Sci Ther 9: 705-708. doi:10.4172/1948-5956.1000494

Copyright: @ 2017 Elamin A, et al. This is an open-access article distributed under the terms of the Creative Commons Attribution License, which permits unrestricted use, distribution, and reproduction in any medium, provided the original author and source are credited. 


\section{D-PAGE}

Protein precipitation and quantification: All tissue protein samples were precipitated using acetone-methanol precipitation procedure. Estimation of protein concentration was done using Smart $\operatorname{spec}^{\mathrm{Tn}}$ and Bio-Rad protein assay (Bradford standard assay) which measures protein concentrations in the range $200 \mu \mathrm{g}$ to $1400 \mu \mathrm{g}$. This in order to enable accurate comparison of the measurements of proteins from different $2 \mathrm{D}$ runs.

IEF with IPG gel strips rehydration and equilibration: Equal amount of protein samples were diluted in rehydration buffer $(8 \mathrm{M}$ Urea, 10 Mm DTT, $1 \%$ CHAPS, $0.25 \%$ Biolyte $\mathrm{pH} 3-10$ ), to make a total volume of $125 \mu \mathrm{l}$ of sample buffer per IPG gel strip (pH 3-10 NL, $7 \mathrm{~cm}$ ), dry strips were actively rehydrated in this solution for 16 hours for 50 $\mathrm{V}$ at $20^{\circ} \mathrm{C}$ and then focused using Protean IEF Cell System. Following IEF gels were equilibrated by gentle shaking for 15 minutes in $5 \mathrm{ml}$ equilibration buffer (6 M Urea, 1\% DTT, 30\% Glycerin, 5\% SDS, 0.05 $\mathrm{M}$ Tris and a trace of bromophenol blue) followed by $5 \mathrm{ml}$ of the same solution containing 2 Iodoacetamide instead of DTT for $15 \mathrm{~min}$.

\section{SDS-PAGE}

The second dimension was performed using the Laemmli method [7]. The IEF gel was positioned on top of a $12.5 \% \mathrm{w} / \mathrm{v}$ SDS-polyacrylamide gel $(70 \mathrm{~mm} \times 70 \mathrm{~mm} \times 1 \mathrm{~mm})$ and sealed with boiling $1 \%$ agarose in running buffer (1.5 M Tris, $\mathrm{pH}$ 8.8). Electrophoresis was run in a BioRad mini protean 3 cooling temperature of $20^{\circ} \mathrm{C}$. Some samples were separated in the second dimension using $12.5 \% \mathrm{w} / \mathrm{v}$ SDS-polyacrylamide gel $(170 \mathrm{~mm} \times 170 \mathrm{~mm} \times 1 \mathrm{~mm})$ and run using Bio-Rad protean II xi equipment.

Staining and visualization: Gels were stained using Coomassie staining [8]. After destaining with deionized water; gels were scanned using GS-800 calibrated densitometer, processed using Quantity one program, spot detection and quantification were carried out using PDQUEST $^{\text {Tw }}$ version 8.1 software from (Bio-Rad).

In-gel digestion, target spotting and MALDI-TOF analysis of proteins: Gels of interest were rinsed with water and spots of interest were cut from the gel manually with a clean scalpel and chopped into small pieces and placed into microcentrifuge tubes. The gel pieces were washed two times with 100-150 $\mu$ l water (HPLC grade) for 5 minutes, acetonitrile twice in order to destain Coomassie stained gel pieces, they were rehydrated into $100-150 \mu \mathrm{l} 100 \mathrm{mM} \mathrm{NH}_{4} \mathrm{HCO}_{3}$, equal volume of acetonitrile had been added for 10-15 min, all liquid was removed, and the gel pieces were shrunk in double amount acetonitrile. This step was repeated three times until the gel pieces are colorless.

Gel pieces were then rehydrated into $15-20 \mu \mathrm{l}$ digestion buffer (100 mM NH $\mathrm{HCO}_{3}, \mathrm{H}_{2} \mathrm{O}, 100 \mathrm{mM} \mathrm{CaCl}_{2}$ ) at $4^{\circ} \mathrm{C}$ for $15-20$ minutes, this step had been repeated twice and then all remaining buffer was removed and 15-20 $\mu$ l of the same buffer (without trypsin) had been added to cover the gel pieces and keep them wet during enzymatic digestion. Samples were left in a heating block overnight $37^{\circ} \mathrm{C}$, gel pieces were spun down, $80 \mu$ l extraction buffer was added containing $10 \%(\mathrm{v} / \mathrm{v})$ formic acid and $100 \%(\mathrm{v} / \mathrm{v})$ acetonitrile $1: 1$. After incubation for 15 minutes at $37^{\circ} \mathrm{C}$ in sonication bath gel pieces were spun down and the supernatant was collected into a separate $0.5 \mathrm{ml}$ tube and double the volume of acetonitrile was added and incubated for 15 minutes in a sonication bath. Then gel pieces were spun down and the supernatant was collected, and the extracts were pooled and dried down using "speed-vac" (at $30^{\circ} \mathrm{C}$ ). After the drying step, the peptides were washed three times by zip tipping with $10 \mu \mathrm{l}$ washing solution containing $50 \%$ acetonitrile, $0.1 \%$ TFA (trifluoroacetic acid). Peptides bound to the column were re-suspended in $2 \mu \mathrm{l}$ of elution buffer and then mixed with 1-2 $\mu$ of the $\alpha$-cyano-4-hydroxycinnamic acid matrix. This mixture was then added to MALDI/TOF target plate and left to dry in a $37^{\circ} \mathrm{C}$ heating plate in order to evaporate the solution and left the peptides mixed with matrix crystals on the target plate. Control digests were performed on gel piece that did not contain any protein and were naturally found at the edge of the gel. Extracted peptides were then analyzed by MALDI/TOF MS (Bio-Rad). The laser wavelength was $120 \mathrm{~nm}$. The MALDI spectra were averaged over 100 laser shots. External calibration pepmix was employed.

Database searches for protein identification: A program available on the internet (http://www.matrixscience.com) was used to search the protein databases. The program Mascot uses peptide mass fingerprints (PMFs) to search databases for matching peptides from known proteins. The following parameters were used in the searches: protein mass ranged from 1000-100000 Dalton, trypsin digest (one missed cleavage allowed), Variable modifications: Oxidation (M), mass accuracy 120 ppm; species: Homo sapiens.

\section{Results}

Differences between normal and neoplastic breast cancer tissue were identified using 2D-PAGE. The overall profile was relatively similar. Proteins that were reproducibly differentially expressed between tumors and controls were circled and numbered some proteins were altered quantitatively whilst some were qualitatively different in gels.

Only six proteins were identified to be differentially expressed between tumors and controls in most $(>60 \%)$ of samples analyzed. Three of which were identified with MALDI-TOF by PMF and matched with known proteins in MASCOT database. These proteins were (Figure 1) (Table 1): (1) Alpha-1-antitrypsin ( $\alpha 1-A T)$ precursor (Alpha-1 protease inhibitor) which was identified to have a molecular mass of $46,878 \mathrm{KDa}$, an isoelectric point (pI) of 5.37 and a score of 85 whereas protein scores greater than 54 are normally significant $(\mathrm{P}<0.05)$ (Figure 2), (2) PeroxiredoxinV, mitochondrial precursor $(\operatorname{Prdx} V)$, which identified to have a molecular mass of 22,298 KDa, an isoelectric point (pI) of 8.85 and a score of 61 (Figure 3), and (3) Peptidyl-prolyl cis-trans isomerase A (Pin1), with a molecular mass of $18,098 \mathrm{KDa}$, an isoelectric point (pI) of 7.82 and a score of 61 (Figure 4).

Besides these three protein spots that were successfully identified, a total of three spots in the malignant group of gels were considered

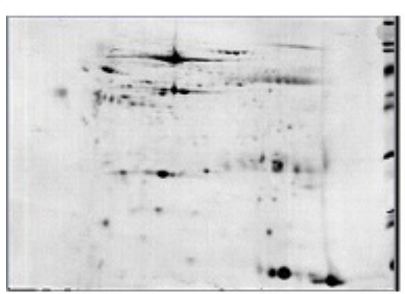

(A)

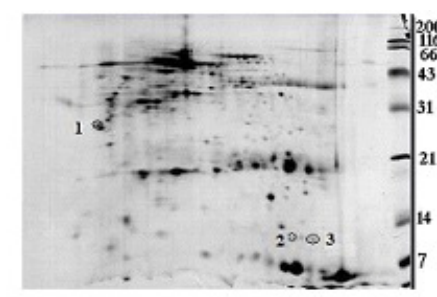

(B)
Figure 1: Representative Coomassie-stained 2D gels of normal (A) and malignant $(B)$ samples, respectively. One hundred twenty-five micrograms of protein had been loaded onto non- linear IPG strips ( $p$ I $3^{\wedge} 10$ ) and isoelectric focusing were performed. The second-dimensional run was carried out on $12.5 \%$ SDS$^{\wedge} P A G E$ gels. Both gels were processed in the same batch. Proteins that were reproducibly differentially expressed are circled and numbered A1AT (1), Peroxiredoxin-5, mitochondrial precursor (2), and Peptidyl-prolyl cis-trans isomerase $\mathrm{A}(3)$. 
Citation: Elamin A, Franz T, Ibrahim ME (2017) Identification of Potential Tumor Markers in Sudanese Breast Cancer Patients Using a Proteomic Approach. J Cancer Sci Ther 9: 705-708. doi:10.4172/1948-5956.1000494

\begin{tabular}{|c|c|c|c|c|c|}
\hline ID & Protein identified & $\begin{array}{c}\text { SWISS-PROT } \\
\text { accession no. }\end{array}$ & Mass (kDa)/pl & Score* & Expect \\
\hline 1 & $\begin{array}{c}\text { Alpha-1-antitrypsin precursor } \\
\text { (Alpha-1 protease inhibitor) }\end{array}$ & P01009 & $46,878 / 5.37$ & 85 & $4.80 \mathrm{E}-05$ \\
\hline 2 & $\begin{array}{c}\text { Peroxiredo-xin5, mitochondrial } \\
\text { precursor }\end{array}$ & P30044 & $22,298 / 8.85$ & 61 & $\begin{array}{c}35-64,161-178,248-250 \\
127-159,216-241,\end{array}$ \\
\hline 3 & \begin{tabular}{c} 
Peptidyl-prolyl cistrans isomerase A \\
\hline
\end{tabular} & P62937 & $18,098 / 7.82$ & 63 & 0.012 \\
\hline
\end{tabular}

Table 1: Catalogue of the protein spots identified; given: Protein name accession numbers (the abbreviations used in the MASCOT database), isoelectric point and molecular weight and the matching score.

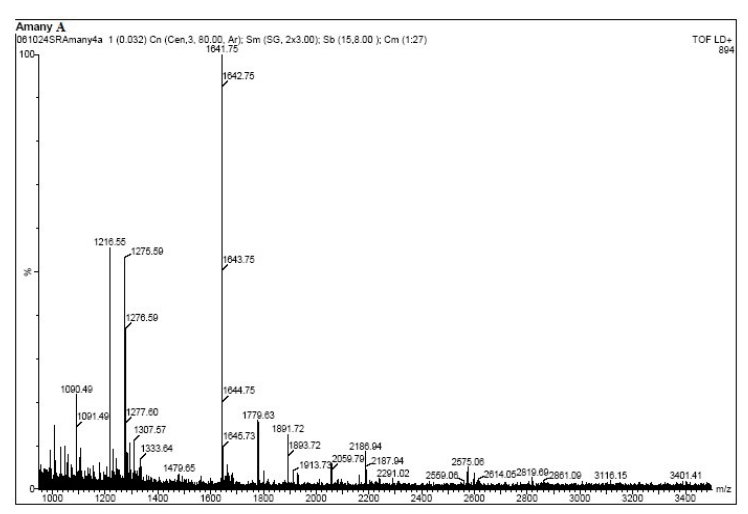

Figure 2: MALDI-TOF mass spectrum of the mixture of tryptic peptides derived from (1) protein spot. (Alpha-1-antitrypsin).

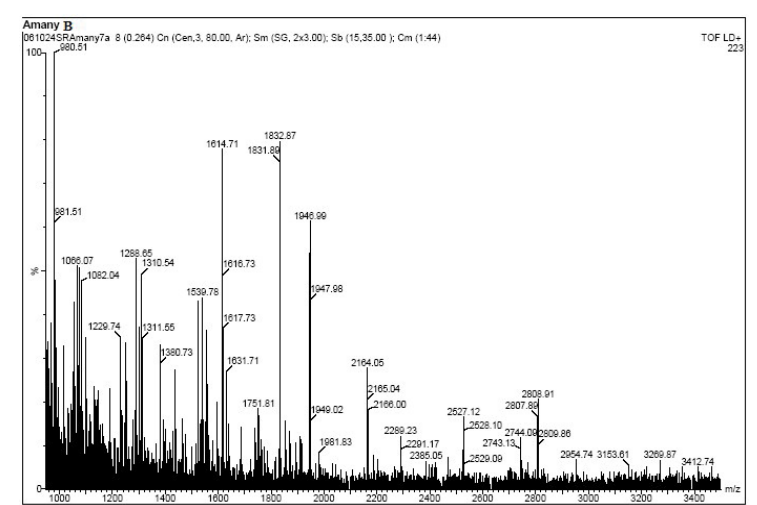

Figure 3: MALDI-TOF mass spectrum of the mixture of tryptic peptides derived from (2) protein spot (Peroxiredoxin-5).

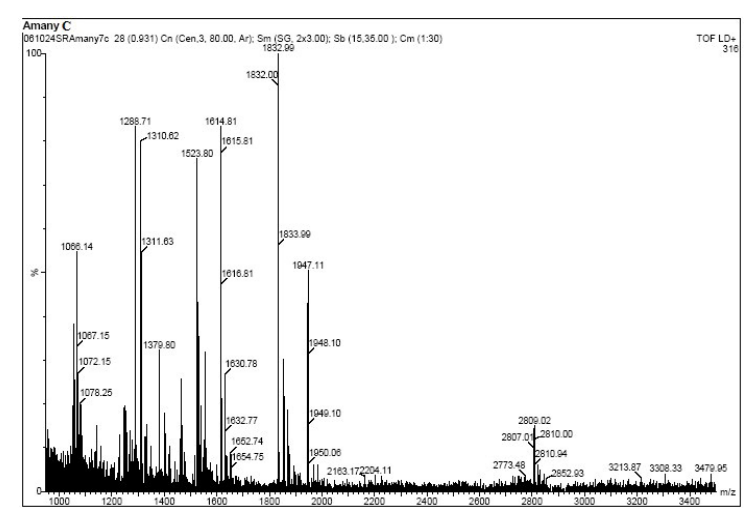

Figure 4: MALDI-TOF mass spectrum of the mixture of tryptic peptides derived from (3) protein spot (Peptidyl-prolyl cis-trans isomerase A). differentially expressed but did not find a statistically acceptable match in the database.

\section{Discussion}

The present work aimed to introduce a contribution to the understanding of proteomic profiling of breast cancer in Sudanese patients. A panel of normal and malignant breast tissue specimens were analyzed in order to identify proteins changes associated with breast carcinogenesis. Proteomic analysis identified a total of 3 differentially expressed proteins between malignant and control tissue samples. Moreover, a total of three spots were found considerably differentially expressed but did not find a statistically acceptable match in the database. This could be explained by the fact that proteins which are covalently modified (e.g., glycoproteins) may present a problem, since it is not easy to predict sites of modification, and thus some of the molecular weights may not match the expected sets of peptide molecular weights for proteins in the database [9].

Three proteins spots differentially expressed in cancer tissue gels were successfully identified with a statistically significant number of molecular weights match. These proteins were: Alpha-1-antitrypsin precursor (Alpha-1 protease inhibitor), Peroxiredoxin $V$ (mitochondrial precursor), and Peptidyl-prolyl cis-trans isomerase A (PPIA).

Alpha-1-antitrypsin $(\alpha 1-A T)$ is a broad-spectrum inhibitor of serine proteases, including trypsin-, chymotrypsin-, and elastase-like enzymes [10]. Its major physiological role is the inhibition of leukocyte elastases released at sites of inflammation. It is present at significant levels in blood and at lower levels in other extra-cellular fluids, including breast milk [11]. Several cultured human tumor cell lines have been shown to produce functionally active $\alpha 1-A T$ including the breast cancer cell line MCF7 [12]. Elevated immuno-staining of $\alpha 1 A T$ has also been described in various tumors, including tumors of the breast $[13,14]$.

The preliminary proteomics analysis included Peroxiredoxin $V$ ( $\operatorname{Prd} x V)$, also known as $\operatorname{Pr} x V, P M P 20, A O E B 166$, or ACR1 [15-17]. It is a member of the Prdxs family of antioxidant proteins which is known to be overexpressed in several different carcinomas $[18,19]$. Many studies indicated that aberrant expression of Prdxs was found in various kinds of cancers. Moreover, some members of Prdxs were thought to be a biomarker of cancer cells [20]. The ubiquitous distribution of $\operatorname{PrdxV}$ and its electron donors suggests that they might play an important antioxidant role in these different sub-cellular compartments. It also prevents p53 dependent generation of Reactive Oxygen Species (ROS) [21].

The third molecule to be suggested is Peptidyl-prolyl cis-trans isomerase A (Pin1), which is known to play important roles in many cellular events, such as cell cycle progression and differentiation. Pin1 is thought to be overexpressed in breast cancer and cooperates with Ras signaling in increasing catalysis for oncogenesis $[22,22]$. Overexpression of Pin 1 promotes tumor growth, while inhibition of Pin 1 causes tumor 
Citation: Elamin A, Franz T, Ibrahim ME (2017) Identification of Potential Tumor Markers in Sudanese Breast Cancer Patients Using a Proteomic Approach. J Cancer Sci Ther 9: 705-708. doi:10.4172/1948-5956.1000494

cell apoptosis. Therefore, it may serve as an effective diagnostic and therapeutic anticancer target acting by blocking cell cycle progression. Many inhibitors of Pin1 were discovered, including several classes of designed inhibitors (alkene isosteres, reduced amides, indanyl ketones) and natural products (juglone, pepticinnamin E analogues, $\mathrm{PiB}$ ) [23]. Validation of identified markers is of utmost importance to ascertain reproducibility and prevent systematic bias and overfitting of data [24]. Validation studies need to be conducted in a separate cohort of breast cancer patients and controls using Immunohistochemistry. Also, the specificity of these markers should be tested in other types of cancers' tissues and controls. Immunohistochemistry [25] also, the specificity of these markers should be tested in other types of cancers' tissues and controls. Only a single conformational study was conducted out of this study up to date. Peroxiredoxin V expression was examined in a separate number of Sudanese breast cancer patients and matching controls using immunohistochemistry and in situ hybridization [26]. Further studies are needed to determine the potential of using identified markers of breast cancer in clinical management.

\section{Conclusion}

Although the number of samples investigated in this study is comparatively small, which constrain outlining authoritative conclusions; this preliminary proteomic study suggests a panel of tumor markers that could have diagnostic, prognostic and/or therapeutic values. Further investigations are needed to validate the data provided in this study and to draw a link between those markers and pathological parameters and therapy.

\section{Acknowledgement}

This piece of work had been performed by an access to the Proteomics Core Facility, European Molecular Biology Laboratory, Heidelberg, Germany, thank go to the laboratory staff for technical support. This study is generously funded by Boehringer Ingelheim Fonds.

\section{Competing Interests}

Authors have no competing interests.

\section{References}

1. Jemal A, Bray F, Center MM, Ferlay J, Ward E, et al. (2011) Global cancer statistics. CA Cancer J. Clin 61: 69-90.

2. Awadelkarim KD, Mariani-Costantini R, Elwali NE (2012) Cancer in the Sudan: An overview of the current status of knowledge on tumor patterns and risk factors. Sci Total Environ 423: 214-228.

3. Hamad HM (2006) Cancer initiatives in Sudan. Ann. Oncol 17: 32-36.

4. Banin Hirata BK, Oda JM, Losi Guembarovski R, Ariza CB, De Oliveira CE, et al. (2014) Molecular markers for breast cancer: Prediction on tumor behavior. Dis Markers: 1-12.

5. Tessitore A, Gaggiano A, Cicciarelli G, Verzella D, Capece D, et al. (2012) Serum biomarkers identification by mass spectrometry in high-mortality tumors. Int J Proteomics 125858.

6. Huang HL, Stasyk T, Morandell S, Dieplinger H, Falkensammer G, et al. (2006) Biomarker discovery in breast cancer serum using 2-D differential ge
electrophoresis/MALDI-TOF/TOF and data validation by routine clinical assays. Electrophoresis 27: 1641-1650.

7. Laemmli UK (1970) Cleavage of structural proteins during the assembly of the head of bacteriophage T4. Nature 227: 680-685.

8. Neuhoff VS, Eibl RH (1985) Clear background and highly sensitive protein staining with Coomassie Blue dyes in polyacrylamide gels: a systematic analysis. Electrophoresis 6: 427-448.

9. Sellers TA, Yates JR (2003) Review of proteomics with applications to genetic epidemiology. Genet. Epidemiol 24: 83-98.

10. Potempa J, Korzus E, Travis J (1994) The serpin superfamily of proteinase inhibitors: structure, function, and regulation. J Biol Chem 269: 15957-15960.

11. McGilligan KM, Thomas DW, Eckhert CD (1987) Alpha-1antitrypsin concentration in human milk. Pediatr Res 22: 268-270.

12. Kataoka H, Nabeshima K, Komada N, Koono M (1989) New human colorectal carcinoma cell lines that secrete proteinase inhibitors in vitro. Virchows Arch $B$ Cell Pathol Incl Mol Pathol 57: 157-165.

13. Hamrita B, Chahed K, Trimeche M, Hammann P, Chaieb A, et al. (2009) Proteomics-based identification of alpha1-antitrypsin and haptoglobin precursors as novel serum markers in infiltrating ductal breast carcinomas. Clin Chim Acta 404: 111-118.

14. Zhou J, Trock B, Tsangaris TN, Friedman NB, Shapiro D, et al. (2010) A unique proteolytic fragment of alpha1-antitrypsin is elevated in ductal fluid of breast cancer patient. Breast Cancer Res Treat 123: 73-86.

15. Knoops B, Clippe A, Bogard C, Arsalane K, Wattiez R, et al. (1999) Cloning and characterization of AOEB166, a novel mammalian antioxidant enzyme of the peroxiredoxin family. J Biol Chem 274: 30451-30458.

16. Kropotov A, Sedova V, Ivanov V, Sazeeva N, Tomilin A, et al. (1999) A novel human DNA-binding protein with sequence similarity to a subfamily of redox proteins which is able to repress RNA-polymerase-III-driven transcription of the Alu-family retroposons in vitro. Eur J Biochem 260: 336-346.

17. Noh DY, Ahn SJ, Lee RA, Kim SW, Park IA et al. (2001) Overexpression of peroxiredoxin in human breast cancer. Anticancer Res 21: 2085-2090.

18. Karihtala P, Mantyniemi A, Kang SW, Kinnula VL, Soini Y (2003) Peroxiredoxins in breast carcinoma. Clin. Cancer Res 9: 3418-3424.

19. Zhang B, Wang Y, Su Y (2009) Peroxiredoxins, a novel target in cancer radiotherapy. Cancer Lett 286: 154-160.

20. Zhou Y, Kok KH, Chun AC, Wong CM, Wu HW, et al. (2000) Mouse peroxiredoxin $\mathrm{V}$ is a thioredoxin peroxidase that inhibits p53-induced apoptosis. Biochem Biophys Res Commun 268: 921-927.

21. Wulf GM, Ryo A, Wulf GG, Lee SW, Niu T, et al. (2001) Pin1 is overexpressed in breast cancer and cooperates with Ras signaling in increasing the transcriptional activity of c-Jun towards cyclin D1. Embo J 20: 3459-3472.

22. Yamashita H, Avraham S, Jiang S, London R, Veldhoven PP, et al. (1999) Characterization of human and murine PMP20 peroxisomal proteins that exhibit antioxidant activity in vitro. J Biol Chem 274: 29897-29904.

23. Xu GG, Etzkorn FA (2009) Pin1 as an anticancer drug target. Drug News Perspect 22: 399-407.

24. Gown AM (2002) Genogenic immunohistochemistry: a new era in diagnostic immunohistochemistry. Current Diagnostic Pathol 8: 193-200.

25. Gast MC, Schellens JH, Beijnen JH (2009) Clinical proteomics in breast cancer: a review. Breast Cancer Res Treat 116: 17-29.

26. Elamin A, Zhu H, Hassan AM, Xu N, Ibrahim ME (2013) Peroxiredoxin V: A candidate breast tumor marker of population specificity. Mol Clin Oncol 1: 541-549. 